OPEN ACCESS

Edited by:

Riccardo Masetti,

University of Bologna, Italy

Reviewed by:

Anna Maria Testi,

Sapienza University of Rome, Italy

Daniele Zama

Sant'Orsola-Malpighi Polyclinic, Italy

*Correspondence:

Szymon Skoczeń

szymon.skoczen@uj.edu.pl

Specialty section

This article was submitted to

Pediatric Hematology and

Hematological Malignancies,

a section of the journal

Frontiers in Pediatrics

Received: 11 November 2019 Accepted: 20 February 2020

Published: 20 March 2020

Citation:

Czogała M, Pawińska-Wạsikowska K, Książek T, Sikorska-Fic B, Matysiak M, Rodziewicz-Konarska A, Chybicka A, Skalska-Sadowska J, Wachowiak J, Muszyńska-Rosłan K,

Krawczuk-Rybak M, Grabowski D, Kowalczyk J, Zielezińska K, Urasiński T, Tomaszewska $R$

Szczepański T, Karpińska-Derda I, Woszczyk M, Pohorecka J, Karolczyk G, Młynarski W, Mycko K,

Badowska W, Skoczeń S and

Balwierz W (2020) Treatment

Outcome and the Genetic

Characteristics of Acute Promyelocytic Leukemia in Children in Poland From

2005 to 2018. Front. Pediatr. 8:86.

doi: 10.3389/fped.2020.00086

\section{Treatment Outcome and the Genetic Characteristics of Acute Promyelocytic Leukemia in Children in Poland From 2005 to 2018}

\begin{abstract}
Małgorzata Czogała 1,2, Katarzyna Pawińska-Wąsikowska ${ }^{1,2}$, Teofila Książek ${ }^{2,3}$, Barbara Sikorska-Fic ${ }^{4}$, Michał Matysiak ${ }^{4}$, Anna Rodziewicz-Konarska ${ }^{5}$, Alicja Chybicka ${ }^{5}$, Jolanta Skalska-Sadowska ${ }^{6}$, Jacek Wachowiak ${ }^{6}$, Katarzyna Muszyńska-Rosłan ${ }^{7}$, Maryna Krawczuk-Rybak ${ }^{7}$, Dominik Grabowski ${ }^{8}$, Jerzy Kowalczyk ${ }^{8}$, Karolina Zielezińska ${ }^{9}$, Tomasz Urasiński ${ }^{9}$, Renata Tomaszewska ${ }^{10}$, Tomasz Szczepański ${ }^{10}$, Irena Karpińska-Derda ${ }^{11}$, Mariola Woszczyk ${ }^{11}$, Joanna Pohorecka ${ }^{12}$, Grażyna Karolczyk ${ }^{12}$, Wojciech Młynarski ${ }^{13}$, Katarzyna Mycko ${ }^{14}$, Wanda Badowska ${ }^{14}$, Szymon Skoczen ${ }^{1,2 *}$ and Walentyna Balwierz ${ }^{1,2}$
\end{abstract}

\begin{abstract}
${ }^{1}$ Department of Pediatric Oncology and Hematology, Institute of Pediatrics, Jagiellonian University Medical College, Krakow, Poland, ${ }^{2}$ Department of Pediatric Oncology and Hematology, University Children Hospital, Krakow, Poland, ${ }^{3}$ Department of Medical Genetics, Institute of Pediatrics, Jagiellonian University Medical College, Krakow, Poland, ${ }^{4}$ Department of Pediatrics, Hematology and Oncology, Medical University of Warsaw, Warsaw, Poland, ${ }^{5}$ Department of Bone Marrow Transplantation, Pediatric Oncology and Hematology, Medical University of Wroclaw, Wroclaw, Poland, ${ }^{6}$ Department of Pediatric Oncology, Hematology and Transplantology, Poznan University of Medical Sciences, Poznan, Poland, ${ }^{7}$ Department of Pediatric Oncology and Hematology, Medical University of Bialystok, Bialystok, Poland, ${ }^{8}$ Department of Pediatric Hematology, Oncology and Transplantology, Medical University of Lublin, Lublin, Poland, ${ }^{9}$ Department of Pediatrics, Hematology and Oncology, Pomeranian Medical University, Szczecin, Poland, ${ }^{10}$ Department of Pediatrics Hematology and Oncology, Medical University of Silesia, Zabrze, Poland, "'Department of Pediatrics, Hematology and Oncology, City Hospital, Chorzów, Poland, ${ }^{12}$ Paediatric Department of Hematology and Oncology, Regional Polyclinic Hospital in Kielce, Kielce, Poland, ${ }^{13}$ Department of Pediatrics, Oncology, Hematology and Diabetology, Medical University of Lodz, Lodz, Poland, ${ }^{14}$ Department of Pediatrics and Hematology and Oncology, Province Children's Hospital, Olsztyn, Poland
\end{abstract}

Background: The aim of the study was to analyze the treatment outcome and genetic characteristics of acute promyelocytic leukemia (APL) in children in Poland from 2005 to 2018.

Methods: All 41 patients diagnosed with APL in Poland during the analysis period were eligible for the study. In period I (2005-2015), 33 patients were treated with chemotherapy and all-trans retinoic acid (ATRA), and in period II (2015-2018), 3 patients (high risk) received induction chemotherapy with ATRA and arsenic trioxide (ATO), and 5 patients (standard risk) received ATRA and ATO without chemotherapy.

Results: Probability of 5-years overall survival (OS), event-free survival (EFS), and relapse-free survival (RFS) was $0.819 \pm 0.069,0.831 \pm 0.063$, and $0.961 \pm 0.037$, respectively, in the whole cohort. Four (11\%) early deaths were observed. One patient died of severe infection in the course of disease progression. Relapse occurred in one patient, who died finally because of disease progression. All events occurred in the patients from period I. Variant APL was identified in one patient (successfully treated with chemotherapy with ATRA) and complex translocation in one patient (the only patient with relapse). Additional chromosomal aberrations were found in $26 \%$ of patients and 
FLT3-ITD mutation was detected in $44 \%$ of patients; none of those changes influenced clinical outcome.

Conclusion: Treatment outcome in the analyzed group is similar to the results reported by other study groups. The main cause of death was coagulation disorders in the early stage of disease. Early, accurate diagnosis followed by specific treatment enables the reduction in the number of early deaths.

Keywords: acute promyelocytic leukemia, children, variant translocations, treatment results, ATO, ATRA

\section{INTRODUCTION}

Acute promyelocytic leukemia (APL) is a specific subtype of acute myeloid leukemia (AML). In most cases, it is characterized by translocation $(15 ; 17)$ with the PML-RARA fusion gene $(1-3)$, but about $1-2 \%$ of APL cases are due to rare variant translocations including ZBTB16/RARA, NMP/RARA, NUMA/RARA, STAT5B/RARA, PRKAR1a/RARA, BCOR/RARA, and FIP1L1/RARA (4-6). APL comprises about $5-10 \%$ of pediatric AML (1) and about $0.4 \%$ of all malignancies in children. Methods of the treatment used in children are based on clinical studies performed on greater adult population. Until the late 1980's, APL was the most lethal subtype of AML $(2,3)$. The result of the treatment improved significantly since the 1980's when specific treatment with all-trans retinoic acid (ATRA) was introduced (2, 3, 7-9). Since the 1990's, another specific drug-arsenic trioxide (ATO) - has been implemented. Efficacy and safety were first proven in adult patients (10-12) followed by the studies in children $(1,13-16)$. The combination of ATRA, ATO, and anthracycline-based chemotherapy ensures remission achievement in almost all patients $(1,13-16)$. Use of the specific treatment in APL allowed reduction of the chemotherapy especially cumulative anthracycline doses $(13,15-17)$. The main causes of the treatment failure are still early deaths, mostly in the course of intracranial hemorrhage $(2,3,18)$. In the large analysis comprising 683 patients from different international studies, initial high WBC counts and obesity were found as likely predictors of thrombohemorrhagic early deaths in childhood APL (18).

Here, we present retrospective analysis of the treatment results of pediatric APL in Poland from 2005, when genetic analysis became widely available to confirm diagnosis of APL, to 2018. Children were treated according to two consecutive protocols, first (2005-2015) based on combination of chemotherapy and ATRA and second (2015-2018) based on ATRA and ATO with or without chemotherapy depending on number of leukocytes at diagnosis.

The aims of the study were to assess clinical outcome and determine the causes of treatment failures. We also performed analysis of additional genetic changes found in APL patients.

\section{PATIENTS AND METHODS}

From January 2005 to December 2018, 41 children (age 018) with newly diagnosed APL were treated in 16 centers of the Polish Pediatric Leukemia and Lymphoma Study Group.
They comprised $6.5 \%$ of all 627 pediatric patients diagnosed with AML in that period. They were treated according to two consecutive protocols (AML-BFM 2004 Interim and AML-BFM 2012). Patient characteristics are summarized in Table 1. All of them were eligible for the study. The last patient was enrolled in May 2018 and the last follow-up was done in December 2018. Median observation time was 61.7 months (range, 7.0-145.5 months). The data were collected in Polish AML registry and analyzed retrospectively.

Informed consent to participation in the studies was obtained from guardians of all patients, in accordance with the Declaration of Helsinki. The study was approved by the Ethics Committee of Jagiellonian University Medical College.

All patients with characteristic bone marrow morphology and immunophenotype had diagnosis confirmed by the use of conventional cytogenetics, showing $\mathrm{t}(15 ; 17)$ or variant translocations, and/or by fluorescence in situ hybridization tests for PML/RARa fusion or positive reverse transcription polymerase chain reaction (RT-PCR) assay.

The FLT3-ITD mutation analyses were routinely performed in all children. Patients were also screened for additional chromosomal aberrations.

In the first period (January 2005-June 2015, period I) 33 patients were treated according to AML-BFM 2004 Interim Protocol; in the second period (July 2015-December 2018, period II) 8 children were treated according to AML-BFM 2012 Protocol. In period I, treatment consisted of four intensive chemotherapy cycles (AIE: cytarabine, idarubicine, etoposide, AI: cytarabine, idarubicine, haM: high-dose cytarabine, mitoxantron, HAE: high-dose cytarabine, etoposide; additional intrathecal cytarabine in every cycle) and maintenance

TABLE 1 | Characteristics of the patients.

\begin{tabular}{|c|c|c|c|c|}
\hline & & $\begin{array}{c}\text { Total } \\
n=41\end{array}$ & $\begin{array}{c}\text { Period I } \\
\text { AML-BFM 2004 } \\
\text { Interim (2005-2015) } \\
n=33\end{array}$ & $\begin{array}{c}\text { Period II } \\
\text { AML-BFM 2012 } \\
(2015-2018) \\
n=8\end{array}$ \\
\hline \multicolumn{2}{|c|}{ Age, years } & 12.4 & 12.34 & 13.51 \\
\hline \multicolumn{2}{|c|}{ median (range) } & $(0.1-17.9)$ & $(0.1-17.9)$ & $(3.7-17.8)$ \\
\hline \multirow[t]{2}{*}{ Gender } & Males & 21 (51\%) & $18(54.5 \%)$ & 3 (37\%) \\
\hline & Females & 20 (49\%) & 15 (45.5\%) & $5(63 \%)$ \\
\hline \multirow{2}{*}{\multicolumn{2}{|c|}{$\begin{array}{l}\text { Observation time, months } \\
\text { median (range) }\end{array}$}} & 61.7 & 61.7 & 18.4 \\
\hline & & $(7.0-145.5)$ & $(12.7-145.5)$ & $(7.0-30.0)$ \\
\hline
\end{tabular}




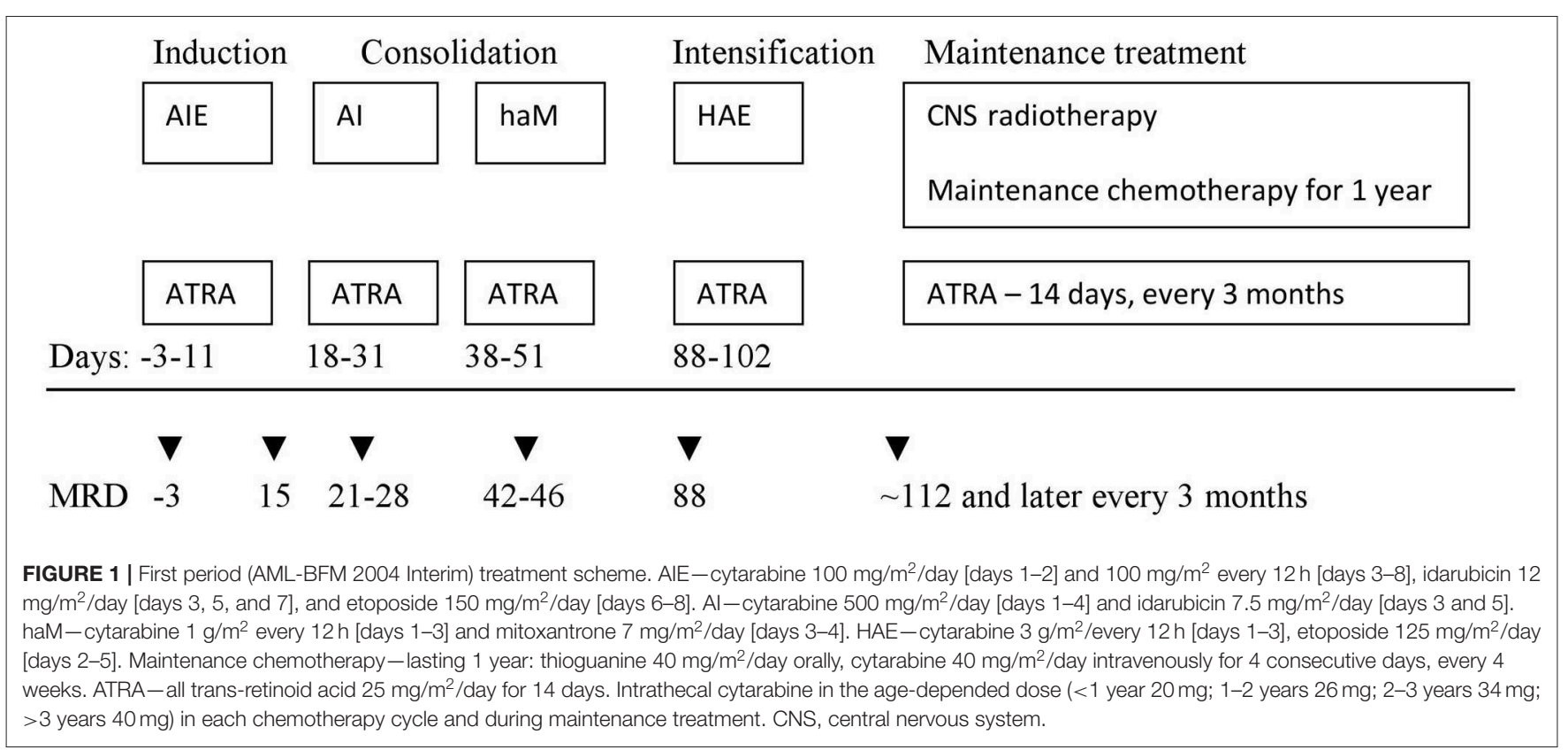

therapy (6-thioguanine, cytarabine) for 1 year. All patients received ATRA concomitant with chemotherapy in 14-days cycles (Figure 1). Median observation time was 61.7 months (12.7-145 months).

In period II, according to the AML-BFM 2012 Protocol, patients with APL were classified into two groups according to initial number of white blood cells (WBC). There were five patients in the standard risk (SR) group with initial WBC $<10,000 / \mu l$ treated with the ATRA and ATO regimen. Three other patients were in the high-risk (HR) group (WBC more than $10.000 / \mu \mathrm{l}$ ), and received one chemotherapy cycle (AI: cytarabine, idarubicine) with ATRA and ATO (Figure 2). Median observation time was 18.4 months (range, 7.0-30 months).

Molecular response was assessed centrally according to Europe Against Cancer program (19). It was monitored in period II, while the data from period I are very limited (complete data from 1 patient and two results in 5 patients -15 and 24 months from diagnosis). In period II and in 1 patient from period I, molecular minimal residual disease (MRD) was monitored on days $21,56,84$, and 112 from the beginning of the treatment and then every 3 months for 12 months in the SR group and 18 months in the HR group.

In our database, we also collected data about differentiation syndrome (DS), severe adverse effect of ATO, and long-lasting consequences of the treatment in patients observed for at least 18 months. DS was defined as having at least three of the following symptoms: unexplained fever, weight gain, dyspnea, and pulmonary infiltrates.

The data that support the findings of the study are available on request from the corresponding author. The data are not publicly available due to privacy or ethical restrictions.

\section{Statistical Analysis}

Descriptive statistical analysis was performed to assess patient baseline characteristics. We used Fisher's exact test or a chisquare test (categorical variables) and Mann-Whitney test (continuous variables) for analysis of clinical and laboratory features. Early mortality was defined as death within 42 days of the induction therapy. Overall survival (OS), event-free survival (EFS), and disease-free survival (DFS) were calculated using the Kaplan-Meier method. OS was defined as the time diagnosis to death from any cause; patients alive or lost to follow-up were censored at the date they were last known alive. EFS was defined as the time from diagnosis to disease progression, relapse, or death from any cause. Patients who were alive without disease progression or relapse were censored at the last time they were seen alive and event-free. DFS was defined as the time from complete remission (CR) to disease relapse, or death from any cause. Patients who were alive without disease relapse were censored at the time of last follow-up. For comparisons of Kaplan-Meier curves, we used the log-rank test. Because there were just eight patients in period II and observation time was much shorter than that in period I, we did not perform any statistical analysis to compare these two periods. All statistical analyses were performed using STATISTICA 12 software.

\section{RESULTS}

\section{Genetic Aberrations}

In 27 patients (65.8\%), complete cytogenetic analysis was available. Variant APL with $\mathrm{t}(11 ; 17)$ ( $\mathrm{q} 23 ; \mathrm{q} 12)$ was identified in one patient and complex translocation involving chromosomes 4, 15, 16, and 17 in another patient (Table 2).

Additional chromosomal aberrations were found in seven patients (26\% of 27 patients with available karyotype results). We identified the trisomy of chromosome 8 in three patients, derivated chromosome 8 in one patient, complex karyotype in two patients (involving chromosomes 3 and 9 with marker chromosome in one patient and involving chromosome 6 with two marker chromosomes in one patient), and additional material from chromosome 16 in the above-described patient 


\section{Standard risk (WBC at diagnosis $<10000 / \mu 1)$}

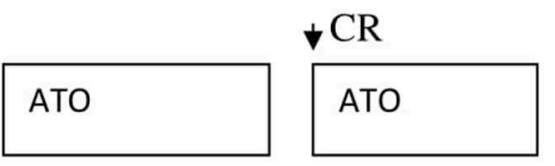

Days 10-42

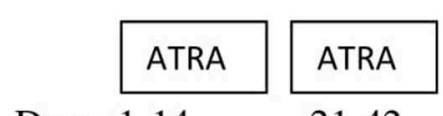

Days: 1-14

56-84 molocular remission

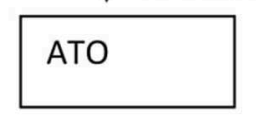

4xATO following CR

98-126

\begin{tabular}{|c|c|c|c|c|c|c|}
\hline & $\nabla$ & $\nabla$ & $\nabla$ & $\nabla$ & $\nabla$ & $\nabla$ \\
\hline MRD & 1 & 28 & 56 & 84 & 112 & $\begin{array}{l}\text { every } 3 \text { months until } \\
12 \text { months }\end{array}$ \\
\hline
\end{tabular}

High risk (WBC at diagnosis $\geq 10000 / \mu \mathrm{l}$ )

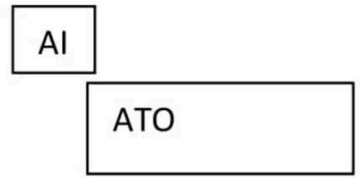

Days 10-42

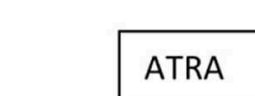

Days: 1-14

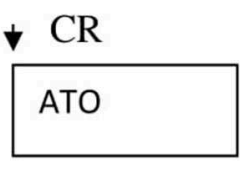

56-84

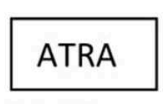

84-98
7XATRA following CR

12 months

\begin{tabular}{lllllll}
\hline & $\boldsymbol{\nabla}$ & $\boldsymbol{\nabla}$ & $\boldsymbol{\nabla}$ & $\boldsymbol{\nabla}$ & $\boldsymbol{\nabla}$ & $\boldsymbol{\nabla}$ \\
MRD & 1 & 28 & 56 & 84 & 112 & every 3 months until \\
i.th. & starting day & 10, every & 4 weeks, in total $7 \mathrm{x}$ & & 12 months
\end{tabular}

FIGURE 2 | Second period (AML-BFM 2012) treatment scheme. Al-cytarabine 100 mg/m²/day [days 1-2] and 100 mg/m² every 12 h [days 3-8], idarubicin 12 $\mathrm{mg} / \mathrm{m}^{2} /$ day [days 3, 5, and 7]. ATRA-all trans-retinoid acid $25 \mathrm{mg} / \mathrm{m}^{2} /$ day oral in two divided doses for 14 days. ATO-arsentrioxide $0.15 \mathrm{mg} / \mathrm{kg} /$ day, starting at day 10 until morphologic CR, after 2 weeks brake: 4 cycles Monday-Friday 0.15 mg/kg/day i.v. for 4 weeks and 4 weeks break. MRD, minimal residual disease; i.th., intrathecal cytarabine in the age-depended dose (<1 year $20 \mathrm{mg} ; 1-2$ years $26 \mathrm{mg} ; 2-3$ years $34 \mathrm{mg} ;>3$ years $40 \mathrm{mg}$ ). CR, complete remission.

with complex translocation involving chromosomes $4,15,16$, and 17 (Table 2).

Result of FLT3-ITD mutation analysis was available in 32 (78\%) patients. This mutation was detected in 14 patients (44\%).

\section{Treatment Response and the Treatment Failures}

Thirty six (88\%) patients achieved complete hematological remission. Data concerning molecular response were available in nine patients (one from period I and eight from period II). On day 21, molecular MRD was negative in two of seven patients with available result, and on day 56, it was negative in seven of eight patients with available results from that time point. All nine patients with available molecular monitoring had negative MRD results from day 84 . No molecular relapse occurred. Four (9.7\%) early deaths (5-10 days from diagnosis) caused by severe coagulation disorders were observed. Nine patients (21.9\%) suffered from severe bleedings including those four children who died. One patient $(2.4 \%)$ died of severe infection in the course of disease progression 1.9 months after diagnosis (no data 
TABLE 2 | Characteristics of the patients with additional genetical changes and variant APL.

\begin{tabular}{|c|c|c|c|c|c|c|c|}
\hline & Genetics & $\begin{array}{c}\text { Age } \\
\text { (years) }\end{array}$ & $\begin{array}{c}\text { WBC } \\
\left(\times 10^{9} / \text { L }\right)\end{array}$ & $\begin{array}{c}\text { PLT } \\
\left(\times 10^{9} / \mathrm{L}\right)\end{array}$ & Complications & Outcome & $\begin{array}{l}\text { Observation time } \\
\text { (months) }\end{array}$ \\
\hline 1 & 46,XY,t(11;17)(q23;q12) & $<1$ & 72.8 & 236 & ND & Alive & 14.7 \\
\hline 2 & $\begin{array}{l}\text { 46,XY,der(4)(4pter } \rightarrow \text { 4q26::16q22 } \rightarrow \\
\text { 16qter), der(15)(15pter } \rightarrow 15 \mathrm{q} 23:: 4 \mathrm{q} 3 \\
1.3 \rightarrow 4 \mathrm{qter}), \operatorname{der}(16)(16 \mathrm{q} 22 \rightarrow 16 \mathrm{p} 11.2 \\
:: 17 \mathrm{q} 25 \rightarrow 17 \mathrm{q} 21:: 16 \mathrm{p} 11.2:: \rightarrow 16 \text { pter)[20] } \\
\text { PML/RARA(+), FLT3-ITD (-) }\end{array}$ & $1-5$ & 21.2 & 8 & - & $\begin{array}{l}\text { Death in course } \\
\text { of progression } \\
\text { after II relapse }\end{array}$ & 37.7 \\
\hline 3 & $\begin{array}{l}\text { 45-47, XX,-6, add (6)(p25), } \\
\text { t(5,17)(q22;q21),+mar, +mar } \\
(7) / 46 X X, P M L / R A R A(+), M L L(-), F L T 3-I T D(-)\end{array}$ & $1-5$ & 5.2 & 7 & $\begin{array}{l}\text { Subcutaneous } \\
\text { and gingival } \\
\text { bleeding }\end{array}$ & Alive & 95.0 \\
\hline 4 & $\begin{array}{l}47, X X,+8, t(15 ; 17)(q 22 ; q 21) ; P M L / R A R A(+) \\
\text { FLT3-ITD(-), }\end{array}$ & $15-18$ & 32.3 & 23 & $\begin{array}{l}\text { DIC, ATRA } \\
\text { syndrome }\end{array}$ & Alive & 35.0 \\
\hline 5 & $\begin{array}{l}\text { 46,XY,add(3),add(9),t(15;17), +mar; } \\
\text { PML/RARA(+) }\end{array}$ & $1-5$ & 0.45 & 20 & - & Alive & 56.6 \\
\hline 6 & $47 X X,+8, t(15,17)(q 22, q 21)$ & $10-15$ & 2.0 & 187 & ATRA syndrome & Alive & 83.6 \\
\hline 7 & $\begin{array}{l}\text { 46,XY, t(15,17)(q22,q21)[9]/47XY+8; } \\
\text { FLT3-ITD(-) }\end{array}$ & $1-5$ & 4.7 & 5 & - & Alive & 92.3 \\
\hline 8 & $\begin{array}{l}\text { 46XY, t(15;17)(q22.q21)[5]/46XY, } \\
\text { t(15;17)(q22,q21), der(8)(pterq24 ...q11 qter), } \\
\text { PML/RARA (+), FLT3-ITD(-) }\end{array}$ & 13 & 20.0 & 24 & - & Alive & 61.7 \\
\hline
\end{tabular}

WBC, number of white blood cells at diagnosis; PLT, number of platelets at diagnosis; ND, no data; DIC, disseminated intravascular coagulation; ATRA, all trans-retinoic acid.

TABLE 3 | Characteristic of the patients with the treatment failure.

\begin{tabular}{|c|c|c|c|c|c|c|c|}
\hline & $\begin{array}{c}\text { Age } \\
\text { (years) }\end{array}$ & $\begin{array}{c}\text { WBC } \\
\left(\times 10^{9} / \mathrm{L}\right)\end{array}$ & $\begin{array}{c}\text { PLT } \\
\left(\times 10^{9} / \mathrm{L}\right)\end{array}$ & Genetics & Events & $\begin{array}{c}\text { EFS } \\
\text { (months) }\end{array}$ & $\begin{array}{c}\text { OS } \\
\text { (months) }\end{array}$ \\
\hline 1 & $10-15$ & 40 & 26 & $\begin{array}{l}46, X X, t(15 ; 17)(q 22 ; q 21), \text { PML/RARA }(+) \\
\text { FLT3-ITD }(+)\end{array}$ & Early death (DIC, MOF) & 0.17 & 0.17 \\
\hline 2 & $1-5$ & 151 & 0 & PML/RARA (+), FLT3-ITD (+) & $\begin{array}{l}\text { Early death (intracranial } \\
\text { bleeding) }\end{array}$ & 0.2 & 0.2 \\
\hline 3 & $10-15$ & 92 & 30 & 46,XY,t(15;17), FLT3-ITD non-available & $\begin{array}{l}\text { Early death (intracranial } \\
\text { bleeding) }\end{array}$ & 0.3 & 0.3 \\
\hline 4 & $1-5$ & 21 & 8 & $\begin{array}{l}46, X Y, \text { der(4)(4pter } \rightarrow 4 q 26:: 16 q 22 \rightarrow 16 \\
\text { qter), der(15)(15pter } \rightarrow 15 q 23:: 4 q 31.3 \rightarrow \\
\text { 4qter),der } \\
(16)(16 q 22 \rightarrow 16 p 11.2:: 17 q 25 \rightarrow 17 q 21 \\
:: 16 p 11.2:: \rightarrow 16 \text { pter) (20) PML/RARA(+), } \\
\text { FLT3-ITD }(-)\end{array}$ & $\begin{array}{l}\text { Relapse, death in progression } \\
\text { after second relapse }\end{array}$ & 17.3 & 37.7 \\
\hline 5 & $10-15$ & 24 & 6 & 46,XY,t(15;17), FLT3-ITD(-) & Death in progression & 0 & 1.87 \\
\hline 6 & $1-5$ & 196 & 21 & $\begin{array}{l}\text { PML/RARA (+), FLT3-ITD analysis } \\
\text { non-available }\end{array}$ & Early death (DIC, leukostasis) & 0.33 & 0.33 \\
\hline
\end{tabular}

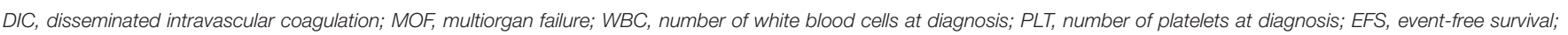
OS, overall survival.

concerning molecular MRD were available). Relapse occurred in one patient (2.4\%), 17 months after first hematological remission. That was the patient with complex translocation. The patient did not respond to second-line chemotherapy (Idarubicine, Fludarabine) with ATRA, but achieved hematological remission after ATO treatment, followed by hematopoietic stem cell transplantation (HSCT). Fourteen months after HSCT, second relapse confirmed by molecular examination occurred, and the patient died 2 months later despite second-line therapy because of disease progression. No data concerning molecular response are available in that patient. Table 3 displays characteristics of the patients with the treatment failures. All events occurred in the patients from period I. There was no event in patients diagnosed after 2011 (21/41 children, 51\%). Treatment results in two periods are presented in Table 4.

\section{Analysis of Survival}

The probability of 5 -years OS, EFS, and RFS was $0.832 \pm 0.069$, $0.848 \pm 0.066$, and $0.964 \pm 0.035$, respectively, for all analyzed patients (Figure 3).

White blood cell count at diagnosis was significantly higher in children who died early compared to the other patients (median 
[range]: $121 \times 10^{3} / \mu \mathrm{l}\left[40-196 \times 10^{3} / \mu \mathrm{l}\right]$ vs. $5.2 \times 10^{3} / \mu \mathrm{l}$ $\left.\left[0.45-140 \times 10^{3} / \mu \mathrm{l}\right], p=0.003\right)$.

Patients with more than $10,000 / \mu \mathrm{l}$ WBC at diagnosis had significantly lower probability of 5-years OS and EFS compared to patients with $\mathrm{WBC}<10,000 / \mu l$ at diagnosis ( 1.0 vs. $0.63, p=$ 0.004 and 1.0 vs. $0.67, p=0.005$, respectively) (Figure 4).

The time from diagnosis to ATRA introduction did not differ between patients with treatment failure and other patients [median (range): $2(1-4)$ days vs. 3 (0-56 days) $p=0.67$ ].

There was no significant difference in OS, EFS, and DFS between patient FLT3-ITD positive and FLT3-ITD negative. Among 14 FLT3-ITD-positive patients, two early deaths occurred (14.3\%), compared to 1 early death (5.5\%), 1 progression (5.5\%), and 1 relapse (5.5\%) in 18 FLT3-ITD-negative patients. Number

TABLE 4 | The treatment results in two consecutive periods.

\begin{tabular}{lccc}
\hline & $\begin{array}{c}\text { Total } \\
\boldsymbol{n = 3 7}\end{array}$ & $\begin{array}{c}\text { Period I } \\
\text { AML-BFM 2004 } \\
\text { Interim } \\
(\mathbf{2 0 0 5 - 2 0 1 5 ) ~} \boldsymbol{n}=\mathbf{3 3}\end{array}$ & $\begin{array}{c}\text { Period II } \\
\text { AML-BFM 2012 } \\
\mathbf{( 2 0 1 5 - 2 0 1 8 )} \\
\mathbf{n = 8}\end{array}$ \\
\hline $\begin{array}{l}\text { Complete remission } \\
\text { (CR) achieved (\%) }\end{array}$ & $36(87.8)$ & $28(84.8)$ & $8(100)$ \\
Early deaths (\%) & $4(9.7)$ & $4(12.2)$ & 0 \\
Death in progression (\%) & $1(2.4)$ & $1(3)$ & 0 \\
Relapse (\%) & $1(2.4)$ & $1(3)$ & 0 \\
Continuous CR (\%) & $35(85.3)$ & $27(81.8)$ & $8(100)$ \\
Severe bleedings (\%) & $9(21.9)$ & $8(24.2)$ & $1(12.5)$
\end{tabular}

of WBC at diagnosis did not differ significantly in patients with and without FLT3-ITD mutation (median [range]: $18.2 \times$ $10^{9} / \mathrm{L}\left[0.9-150.7 \times 10^{9} / \mathrm{L}\right]$ vs. $6.5 \times 10^{9} / \mathrm{L}\left[0.4-140 \times 10^{9} / \mathrm{L}\right]$, respectively, $p=0.4$ ).

Patients with additional chromosomal aberrations did not differ significantly from patients without those aberrations in terms of survival rates (OS, EFS, and RFS). The only event occurred in the patient with complex translocation and additional material from chromosome 16 who had two relapses and died of the disease progression 36.7 months after diagnosis.

The patient with variant translocation $(11 ; 17)$ was treated successfully with a combination of chemotherapy and ATRA and remains in remission with an observation time of 4 years.

\section{Adverse Events of ATRA and ATO}

DS was observed in $29 \%$ of patients $(9 / 31$, no data from 10 patients), eight of whom were treated with steroids; in three patients, ATRA was held and then restarted.

There were no severe adverse events in patients treated with ATO. Transient rash occurred in one patient at the beginning of the therapy.

\section{Late Consequences of the Treatment}

Data concerning long-lasting consequences of the treatment were available in 23 of 34 patients with an observation time of at least 18 months. One patient was diagnosed with aseptic bone necrosis and one was diagnosed with ischemic stroke of brain. We did not find any long-lasting toxicities in 21 patients $(91 \%)$.

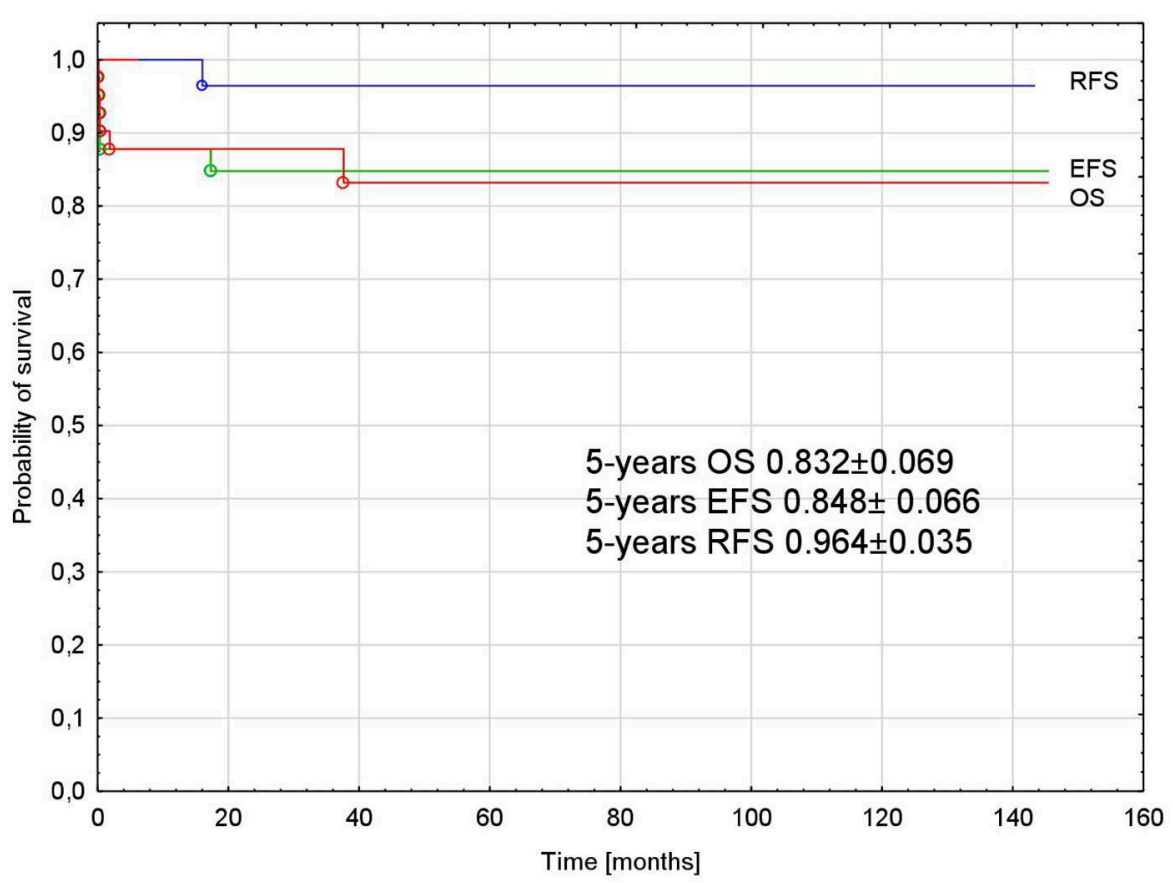

FIGURE 3 | Probability of overall, event-free, and relapse-free survival in all analyzed patients with APL. APL, acute promyelocytic leukemia; OS, overall survival; EFS, event-free survival; RFS, relapse-free survival. 


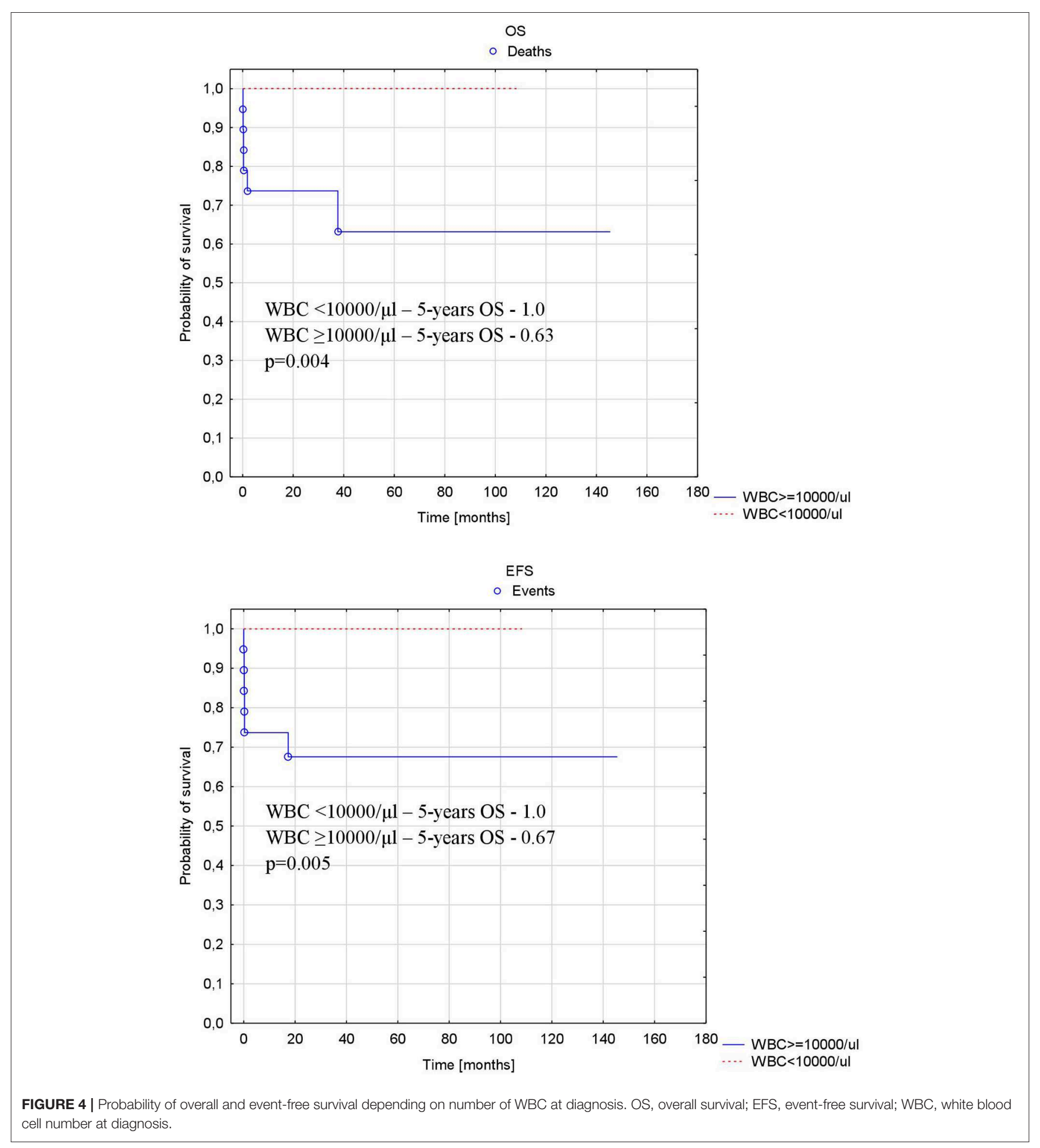

\section{DISCUSSION}

APL comprises about $5-10 \%$ of childhood acute myeloid leukemia (1). In the analyzed period, the percentage of the patients with APL among all children with AML in Poland was $6.5 \%$. The treatment results achieved in the study group
(OS, $0.832 \pm 0.069$; EFS, $0.848 \pm 0.066$; RFS, $0.964 \pm 0.035$ ) are comparable to the results described by other authors $(1,2$, $7,8,13,16,17)$; however, the number of enrolled patients is relatively low. The data concerning molecular monitoring were limited in period I so comparison between two groups was not possible. 
The bleeding complications remain the main cause of the treatment failures in APL. They were found in 4 (9.7\%) patients in our cohort. It is worth noticing that there was no early death in patients with APL in Poland from 2011. It seems that early introduction of ATRA/ATO as well as oncology centers experience reduced the risk of early deaths. New treatment protocol introduced in 2015 with reduction of chemotherapy and use of ATO seems to be very effective. There were no events in that period; however, follow-up was rather short (median 18.4 months).

Variant translocation described as simple translocation involving chromosome 15 or 17 with any other chromosomes or complex translocations characterized by the involvement of additional chromosomes in addition to chromosomes 15 and 17 (4-6, 20-24) was found in two patients in the analyzed group. In one of them, $\mathrm{t}(11 ; 17)(\mathrm{q} 23 ; \mathrm{q} 12)$ was identified, and in the second complex, translocation involving chromosomes 4, 15, 16 , and 17 was found. The first patient was treated successfully with combination of chemotherapy and ATRA and remains in remission with an observation time of 4 years. The patient with complex translocation died of disease progression after second relapse.

Two different variant APL translocations involving chromosomes 11 and 17 were described before, $t(11 ; 17)(\mathrm{q} 23 ; \mathrm{q} 21)$ producing ZBTB16-RARA (formerly PLZF-RARA) fusion gene and $\mathrm{t}(11 ; 17)(\mathrm{q} 13 ; \mathrm{q} 21)$ generating NUMA/RARA $(20,22)$. In cases of APL with $\mathrm{t}(11 ; 17)(\mathrm{q} 23 \mathrm{q} 21)$, there is evidence of resistance to ATRA and ATO both in vivo and in vitro, particularly in those patients who have the reverse rearrangement RAR $\alpha$-PLZF (20), while patients with $t(11 ; 17)(q 13 ; q 21)$ have better prognosis (22).

There are a number of studies concerning the alternate translocation in APL; however, little is still known about the complex variant translocations in $\operatorname{APL}(22,23)$. Both 4,15 , 17 , and $15,16,17$ translocations have been described by other authors $(4,6,22,23)$, but the translocation found in our patient involving four chromosomes $4,15,16$, and 17 has not been reported before.

In our cohort, additional chromosomal aberrations were found in $28 \%$ of patients with complete cytogenetic analysis, with the most common trisomy $8(43 \%)$, similarly described by Cervera et al. (25). All but one patient from that group remain in CR. The only patient with treatment failure (death of disease progression after second relapse) was the child with complex translocation involving chromosomes 4, 15, 16, and 17 with additional material from chromosome 16. Analyzing all patients with additional chromosomal aberration in the study group, no differences in the treatment outcome were found compared to the patients with isolated $\mathrm{t}(15 ; 17)$. It was reported by Cervera et al. that patients with and without additional chromosomal abnormalities had similar CR rates, and despite univariate analysis, they showed that additional chromosomal abnormalities were associated with a lower relapse-free survival in the LPA99 trial; such association was not present in the LPA96 trial. Neither additional chromosomal abnormalities overall nor any specific abnormality was identified as an independent risk factor for relapse in multivariate analysis (25).
In the current study, FLT3-ITD was present in $44 \%$ of patients. This is in accordance with the other studies where the frequency of FLT3-ITD mutation was 20-46\% (26-30). No differences in WBC at diagnosis and the treatment outcome were found in patients with and without FLT3-ITD mutation but analyzed groups were rather small. The prognostic impact of FLT3-ITD mutation in APL remains controversial. Some authors describe negative influence on prognosis. Lucena-Araujo et al. screened for FLT3-ITD mutations in 171 APL patients (including nine children) and reported that FLT3-ITD mutations were associated with high WBC counts and may independently predict a shorter survival in patients with APL treated with ATRA and anthracycline-based chemotherapy (28). Association between FLT3-ITD mutation and high WBC was also confirmed by Barragan et al. in PATHEMA and HAVON groups, but the study did not demonstrate an independent prognostic value of FLT3-ITD mutation in patients with APL treated with ATRA and anthracycline-based regimens (29).

The COG AAML0631 study on childhood APL did not show an association of FLT3-ITD mutations with early death or bleeding/clotting events in induction; however, it was revealed that the relapse rate following ATO consolidation was significantly higher in FLT3-ITD mutant patients (30).

To conclude, the treatment outcome in children with APL in Poland is similar to results reported by other study groups. Reduction of early deaths in the last years was noticed. That could be the effect of introducing ATRA to a treatment protocol and the better experience of the study centers in the care for this challenging group of patients. A new treatment approach with the use of ATO and ATRA without chemotherapy in the SR group or with reduced chemotherapy in HR seems to be safe and effective. The limitation of the study is the relatively low number of enrolled patients. Further studies are needed to confirm the results with longer follow-up.

\section{DATA AVAILABILITY STATEMENT}

The datasets generated for this study are available on request to the corresponding author.

\section{ETHICS STATEMENT}

The studies involving human participants were reviewed and approved by Bioethics Committee of Jagiellonian University Medical College. Written informed consent to participate in this study was provided by the participants' legal guardian/next of kin.

\section{AUTHOR CONTRIBUTIONS}

MC and WBal designed the study. MC, KP-W, BS-F, MM, AR-K, AC, JS-S, JW, KM-R, MK-R, DG, JK, KZ, TU, RT, TS, IK-D, MW, JP, GK, WM, KM, WBad, SS, and WBal were involved in participant recruitment. TK was involved in the laboratory work and interpretation of its results. MC, KP-W, BS-F, AR-K, JS-S, KM-R, DG, KZ, RT, IK-D, JP, and KM collected the clinical data. $\mathrm{MC}$ was involved in the statistical analysis and interpretation 
of its results, and wrote the first draft of the manuscript. WBal, KP-W, and SS edited the first draft of the manuscript. All authors reviewed the manuscript and approved the final version of the manuscript.

\section{FUNDING}

This research was supported by Jagiellonian University Medical College (Projects: K/ZDS/007089 and N41/DBS/000185). The

\section{REFERENCES}

1. Kutny MA, Gregory J Jr, Feusner JH. Treatment of paediatric APL: how does the therapeutic approach differ from adults? Best Pract Res Clin Haematol. (2014) 27:69-78. doi: 10.1016/j.beha.2014.04.007

2. Stein EM, Tallman MS, Stein EM, Tallman MS. Acute promyelocytic leukemia in children and adolescents. Acta Haematol. (2014) 132:30712. doi: $10.1159 / 000365117$

3. Zhang L, Samad A, Pombo-de-Oliveira MS, Scelo G, Smith MT, Feusner J, et al. Global characteristics of childhood acute promyelocytic leukemia. Blood Rev. (2015) 29:101-25. doi: 10.1016/j.blre.2014.09.013

4. Redner RL. Variations on a theme: the alternate translocations in APL. Leukemia. (2002) 16:1927-32. doi: 10.1038/sj.leu.2402720

5. Brunel V, Lafage-Pochitaloff M, Alcalay M, Pelicci PG, Birg F. Variant and masked translocations in acute promyelocytic leukemia. Leuk Lymphoma. (1996) 22:221-8. doi: 10.3109/10428199609051752

6. Xu L, Zhao WL, Xiong SM. Molecular cytogenetic characterization and clinical relevance of additional, complex and/or variant chromosome abnormalities in acute promyelocytic leukemia. Leukemia. (2001) 15:135968. doi: 10.1038/sj.leu.2402205

7. Zwaan CM, Kolb EA, Reinhardt D, Abrahamsson J, Adachi S, Aplenc $\mathrm{R}$, et al. Collaborative efforts driving progress in pediatric acute myeloid leukemia. J Clin Oncol. (2015) 33:2949-62. doi: 10.1200/JCO.2015. 62.8289

8. Fisher BT, Singh S, Huang YS, Li Y, Gregory J, Walker D, et al. Induction mortality, ATRA administration, and resource utilization in a nationally representative cohort of children with acute promyelocytic leukemia in the united states from 1999 to 2009. Pediatr Blood Cancer. (2014) 61:6873. doi: $10.1002 / \mathrm{pbc} .24585$

9. Takahashi H, Watanabe T, Kinoshita A, Yuza Y, Moritake H, Terui K, et al. High event-free survival rate with minimum-dose-anthracycline treatment in childhood acute promyelocytic leukaemia: a nationwide prospective study by the Japanese paediatric leukaemia/lymphoma study group. Br J Haematol. (2016) 174:437-43. doi: 10.1111/bjh.14068

10. Lo-Coco F, Avvisati G, Vignetti M, Thiede C, Orlando SM, Iacobelli S, et al. Retinoic acid and arsenic trioxide for acute promyelocytic leukemia. $N$ Engl J Med. (2013) 369:111-21. doi: 10.1056/NEJMoa1300874

11. Ghavamzadeh A, Alimoghaddam K, Rostami S, Ghaffari SH, Jahani M, Iravani $\mathrm{M}$, et al. Phase II study of single-agent arsenic trioxide for the front-line therapy of acute promyelocytic leukemia. J Clin Oncol. (2011) 29:27537. doi: 10.1200/JCO.2010.32.2107

12. Breccia M, Cicconi L, Lo-Coco F. ATRA + ATO: has a new standard of care been established in low-risk acute promyelocytic leukaemia? Curr Opin Hematol. (2014) 21:95-101. doi: 10.1097/MOH.00000000000 00023

13. Creutzig U, Dworzak MN, Bochennek K, Faber J, Flotho C, Graf N, et al. First experience of the AML-Berlin-Frankfurt-Münster group in pediatric patients with standard-risk acute promyelocytic leukemia treated with arsenic trioxide and all-trans retinoid acid. Pediatr Blood Cancer. (2017) 64:e26451. doi: $10.1002 /$ pbc.26461

14. Cheng Y, Zhang L, Wu J, Lu A, Wang B, Liu G. et al. Long-term prognosis of childhood acute promyelocytic leukaemia with arsenic trioxide administration in induction and consolidation chemotherapy phases: a single-centre experience. Eur J Haematol. (2013) 91:483-9. doi: 10.1111/ejh. 12194 sponsor had no role in the design of the study, analysis, the writing of the manuscript or the decision to submit the manuscript for publication.

\section{ACKNOWLEDGMENTS}

All authors are grateful to the study participants and their parents.

15. Zhou J, Zhang Y, Li J. Single-agent arsenic trioxide in the treatment of children with newly diagnosed acute promyelocytic leukemia. Blood. (2010) 115:1697-702. doi: 10.1182/blood-2009-07-230805

16. Kutny MA, Alonzo TA, Gerbing RB, Wang YC, Raimondi SC, Hirsch BA, et al. Arsenic trioxide consolidation allows anthracycline dose reduction for pediatric patients with acute promyelocytic leukemia: report from the children's oncology group phase III historically controlled trial AAML0631. J Clin Oncol. (2017) 35:3021-9. doi: 10.1200/JCO.2016.71.6183

17. Testi AM, Pession A, Diverio D, Grimwade D, Gibson B, de Azevedo AC, et al. Risk-adapted treatment of acute promyelocytic leukemia: results from the international consortium for childhood APL. Blood. (2018) 132:40512. doi: 10.1182/blood-2018-03-836528

18. Abla O, Ribeiro RC, Testi AM, Montesinos P, Creutzig U, Sung $\mathrm{L}$, et al. Predictors of thrombohemorrhagic early death in children and adolescents with $\mathrm{t}(15 ; 17)$-positive acute promyelocytic leukemia treated with ATRA and chemotherapy. Ann Hematol. (2017) 96:1449-56. doi: 10.1007/s00277-017-3042-6

19. Gabert J, Beillard E, van der Velden VH, Bi W, Grimwade D, Pallisgaard N, et al. Standardization and quality control studies of "real-time" quantitative reverse transcriptase polymerase chain reaction of fusion gene transcripts for residual disease detection in leukemia-a Europe against cancer program. Leukemia. (2003) 17:2318-57. doi: 10.1038/sj.leu.2403135

20. Piñán MA, Balerdi A, Iglesias A. Acute Myeloid Leukemia with $\mathrm{t}(11 ; 17)(\mathrm{q} 23 ; \mathrm{q} 21)$. Ann Hematol Oncol. (2015) 2:1050.

21. Wang Y, Ma J, Liu X, Liu R, Xu L, Wang L, et al. A complex translocation $(3 ; 17 ; 15)$ in acute promyelocytic leukemia confirmed by fluorescence in situ hybridization. Oncol Lett. (2016) 12:4717-19. doi: 10.3892/ol.2016.5280

22. Zhang R, Kim YM, Wang X, Li Y, Pang H, Lee JY, et al. Coexistence of t $(15 ; 17)$ and $\mathrm{t}(15 ; 16 ; 17)$ detected by fluorescence in situ hybridization in a patient with acute promyelocytic leukemia: a case report and literature review. Oncol Lett. (2014) 8:1001-8. doi: 10.3892/ol.2014.2304

23. Liu S, Li Q, Pang W, Bo L, Qin S, Liu X, et al. A new complex variant $\mathrm{t}(4 ; 15 ; 17)$ in acute promyelocytic leukemia: fluorescence in situ hybridization confirmation and literature review. Cancer Genet Cytogenet. (2001) 130:337. doi: 10.1016/S0165-4608(01)00464-2

24. He Y, Wang $\mathrm{P}$, Liang $\mathrm{K}$, Chen $\mathrm{X}$, Du W, Li J, et al. A pediatric acute promyelocytic leukemia with a rare karyotype of $\operatorname{ider}(17)(\mathrm{q} 10) \mathrm{t}(15 ; 17)$ and favorable outcome: a case report. Medicine. (2015) 94:e1778. doi: 10.1097/MD.0000000000001778

25. Cervera J, Montesinos P, Hernández-Rivas JM, Calasanz MJ, Aventín A, Ferro MT, et al. Additional chromosome abnormalities in patients with acute promyelocytic leukemia treated with alltrans retinoic acid and chemotherapy. Haematologica. (2010) 95:424-31. doi: 10.3324/haematol.2009.013243

26. Gallagher RE, Moser BK, Racevskis J, Poiré X, Bloomfield CD, Carroll AJ, et al. Treatment-influenced associations of PMLRAR $\alpha$ mutations, FLT3 mutations, and additional chromosome abnormalities in relapsed acute promyelocytic leukemia. Blood. (2012) 120:2098-108. doi: 10.1182/blood-2012-01-407601

27. Kutny MA, Moser BK, Laumann K, Feusner JH, Gamis A, Gregory J, et al. FLT3 mutation status is a predictor of early death in pediatric acute promyelocytic leukemia: a report from the children's oncology group. Pediatr Blood Cancer. (2012) 59:662-7. doi: 10.1002/pbc.24122

28. Lucena-Araujo AR, Kim HT, Jacomo RH, Melo RA, Bittencourt R, Pasquini $\mathrm{R}$, et al. Internal tandem duplication of the FLT3 gene confers poor overall 
survival in patients with acute promyelocytic leukemia treated with alltrans retinoic acid and anthracycline-based chemotherapy: an international consortium on acute promyelocytic leukemia study. Ann Hematol. (2014) 93:2001-10. doi: 10.1007/s00277-014-2142-9

29. Barragán E, Montesinos $\mathrm{P}$, Camos M, González M, Calasanz MJ, Román-Gómez J, et al. Prognostic value of FLT3 mutations in patients with acute promyelocytic leukemia treated with all-trans retinoic acid and anthracycline monochemotherapy. Haematologica. (2011) 96:1470-7. doi: 10.3324/haematol.2011. 044933

30. Kutny MA, Alonzo TA, Gerbing R, Wang Y-C, Fu C, Aiu $\mathrm{X}$, et al. FLT3 mutations in pediatric acute promyelocytic leukemia; a report from the children's oncology group AAML0631 trial. Blood. (2016) 128:2884 doi: 10.1182/blood.V128.22.28 84.2884
Conflict of Interest: The authors declare that the research was conducted in the absence of any commercial or financial relationships that could be construed as a potential conflict of interest.

Copyright () 2020 Czogała, Pawińska-Wạsikowska, Książek, Sikorska-Fic, Matysiak, Rodziewicz-Konarska, Chybicka, Skalska-Sadowska, Wachowiak, MuszyńskaRosłan, Krawczuk-Rybak, Grabowski, Kowalczyk, Zielezinska, Urasiński, Tomaszewska, Szczepański, Karpińska-Derda, Woszczyk, Pohorecka, Karolczyk, Młynarski, Mycko, Badowska, Skoczen and Balwierz. This is an open-access article distributed under the terms of the Creative Commons Attribution License (CC BY). The use, distribution or reproduction in other forums is permitted, provided the original author(s) and the copyright owner(s) are credited and that the original publication in this journal is cited, in accordance with accepted academic practice. No use, distribution or reproduction is permitted which does not comply with these terms. 